Rafal Tyszkiewicz ${ }^{1}$

\title{
ISTOTA KULTURY BEZPIECZEŃSTWA PRACY W SYSTEMIE ZARZĄDZANIA
}

Streszczenie: Kształtowanie kultury bezpieczeństwa w przedsiębiorstwie wpływa na kształtowanie przewagi konkurencyjnej, poprzez to, iż menedżerowie dostrzegają korzyści płynące z budowania tej kultury, co w konsekwencji zapobiega zagrożeniom w przedsiębiorstwie. Celem artykułu jest identyfikacja znaczenia roli menedżerów w budowaniu kultury bezpieczeństwa w przedsiębiorstwach.

Słowa kluczowe: kultura organizacyjna, kultura bezpieczeństwa, menedżer.

\section{Wprowadzenie}

Dynamicznie rozwijająca się gospodarka sprawia, iż przedsiębiorstwa cały czas budują przewagę konkurencyjną opartą na kulturze organizacyjnej a wraz z nią jej pochodną kulturę bezpieczeństwa.

Kultura bezpieczeństwa pozwala uporządkować i usystematyzować wszystkie działania związane $\mathrm{z}$ bezpieczeństwem i higieną pracy $\mathrm{w}$ organizacji, a jej ideą jest pełne i udokumentowane zaangażowanie zarówno kierownictwa, jak i każdego pracownika na rzecz bezpieczeństwa pracy.

Jednym z podstawowych obowiązków pracodawcy jest ochrona zdrowia i życia pracowników, przez zapewnienie im bezpiecznych i higienicznych warunków pracy. Wśród warunków skutecznego kształtowania tychże warunków odgrywa rolę menedżer przedsiębiorstwa. To od menedżera, jego wiedzy, kompetencji, przewidywania $\mathrm{w}$ procesy bezpieczeństwa i higieny pracy zależy bezpieczne funkcjonowanie każdego działu w przedsiębiorstwie.

Celem artykułu jest identyfikacja znaczenia roli menedżerów w budowaniu kultury bezpieczeństwa w przedsiębiorstwach.

$\mathrm{W}$ artykule postawiono tezę, iż kultura bezpieczeństwa wymaga transformacji kompetencji kierowniczych $\mathrm{w}$ realizacji efektywnych działań $\mathrm{w}$ przedsiębiorstwie. Materiał powstał w oparciu o metodę jakościową w postaci wtórnej analizy danych literaturowych. Jednocześnie stanowi tło teoretyczne do prowadzonych badań empirycznych dotyczących kompetencji menedżerów budujących kulturę

\footnotetext{
${ }^{1}$ Dr, Wyższa Szkoła Bankowa we Wrocławiu, e-mail: rafal.tyszkiewicz@wsb.wroclaw.pl ORCID ID: 0000-0003-1525-0697.
} 
bezpieczeństwa w przedsiębiorstwie. Efektem prowadzonych eksploracji badawczych będzie kolejny materiał prezentowany w postaci raportu z badań.

\section{Kultura organizacyjna a kultura bezpieczeństwa}

Termin „kultura organizacyjna” wprowadzony został do literatury anglojęzycznej w latach sześćdziesiątych XX wieku. Termin „kultura” oznacza całokształt materialnego i duchowego dorobku ludzkości, a także wartości, zasad i norm. Inaczej, kultura organizacyjna to wykształcony oraz zaakceptowany przez byłych i obecnych członków przedsiębiorstwa, członków organizacji zespół wartości wraz z wyrażającymi je zachowaniami [1]. Każdy pracownik organizacji wnosi do niej swój własny system wartości, wtenczas wspólnie podzielane przez wszystkich pracowników wartości nazywamy kultura organizacyjną. Kultura organizacyjna to więc zbiór wspólnych, dla większości ludzi w przedsiębiorstwie, przekonań, nastawień i celów, które bez specjalnych nakazów kształtują sposoby, w jaki działają i współdziałają pracownicy [2].

Można kształtować kulturę organizacyjną w przedsiębiorstwie i ciągle zmieniać ją na lepszą [3]. Wielu praktyków traktuje zmiany kultury organizacyjnej, jako specyficzny byt społeczny, czynnik, zasób, który buduje organizację [4]. Menedżerowie często nie podejmują decyzji o zmianie kultury organizacyjnej $\mathrm{w}$ przedsiębiorstwie, lecz czerpią $\mathrm{z}$ niej wzorce, symbole oraz sposoby komunikowania się. Kulturę organizacyjną w przedsiębiorstwie należy kształtować i zmieniać wraz ze zmianami celów przedsiębiorstwa. $Z$ uwagi na fakt, iż otoczenie organizacji ma charakter dynamiczny, zmiany w organizacji i integralnie $z$ nimi związane zmiany kultury organizacyjnej są procesami trudnymi, jednakże w obecnych czasach dla organizacji nieuchronnymi. Stwarzają one możliwości wyszukiwania i wdrażania coraz to lepszych rozwiązań, procesów, które przyczyniają się do dostosowania przedsiębiorstwa do obecnego lub przyszłego otoczenia [5].

Kultura bezpieczeństwa wywodzi się z kultury organizacji i została po raz pierwszy zdefiniowana na potrzeby praktyki w trakcie sporządzenia raportów z katastrof przemysłowych. Dotyczyło to przede wszystkim awarii reaktora w Czarnobylu i wybuchu na platformie wiertniczej Piper Alpha [6].

Kultura bezpieczeństwa jest terminem często stosowanym zarówno przez praktyków, jaki i naukowców, którzy zajmują się wyjaśnianiem problemów związanych $\mathrm{z}$ bezpieczeństwem $\mathrm{w}$ przedsiębiorstwie. Podobnie jak kultura organizacyjna, kultura bezpieczeństwa pracy obejmuje założenia, normy, podzielane wartości przez członków przedsiębiorstwa, w specyficznym obszarze jego działania, jakim jest bezpieczeństwo [5,7]. 
Zdaniem L. Ostrom, C. Wilhemsen, B. Kaplan kultura bezpieczeństwa to koncepcja, zgodnie z którą organizacyjne wierzenia i postawy, przejawiane działania, polityka i procedury mają wpływ na poziom bezpieczeństwa [8].

Zaś zdaniem J.J. Berendsa kultura bezpieczeństwa to kolektywne zaprogramowanie umysłu nakierowane na bezpieczeństwo grupy członków organizacji [9].

Studenski postrzega kulturę bezpieczeństwa i higieny pracy jako zbiór psychologicznych, społecznych i organizacyjnych czynników uruchamiających lub podtrzymujących działania chroniące życie i zdrowie zarówno w pracy, jak i czynnościach po zawodowych [10].

Kształtowanie kultury bezpieczeństwa w przedsiębiorstwie wpływa na kształtowanie przewagi konkurencyjnej, poprzez to, iż menedżerowie dostrzegają korzyści płynące z budowania tej kultury, co w konsekwencji zapobiega zagrożeniom w przedsiębiorstwie.

Zdaniem E.S. Gellera, kultura bezpieczeństwa pracy w przedsiębiorstwie kształtowana jest poprzez zaangażowanie wszystkich pracowników, pracę w zespołach, poczucie przynależności do przedsiębiorstwa, transfer wiedzy. Przy czym szczególną uwagę należy zwrócić na trzy elementy [11]:

[1.] środowisko fizyczne pracy (narzędzia, maszyny, organizacja stanowisk pracy),

[2.] zachowania pracowników (przestrzeganie przepisów bhp, przekazywanie informacji i współpraca, demonstrowanie troski o bezpieczeństwo wykraczające poza obowiązki),

[3.] cechy wewnętrzne pracowników (wiedza, umiejętności, motywacja).

Zarządzanie kulturą i bezpieczeństwem pracy to poprawa $\mathrm{w}$ przedsiębiorstwie warunków pracy poprzez stosowanie zasad bezpieczeństwa i higieny pracy przez menedżera, często zwanego menedżerem ds. bhp. Coraz większego znaczenia nabiera we współczesnych przedsiębiorstwach jego stanowisko, którego wyrazem jest zaangażowanie $\mathrm{w}$ działania na rzecz zapewnienia poprawy bezpieczeństwa środowiska pracy, kształtowanie wśród pracowników świadomości o zagrożeniach występujących $\mathrm{w}$ procesie pracy, działalność innowacyjna na rzecz rozwiązań dotyczących bezpieczeństwa pracy, prowadzenie analizy ryzyka zawodowego, analizy wypadkowości oraz stworzenie i realizowanie programu reagowania $\mathrm{w}$ nagłych wypadkach [12].

Zarządzanie kulturą i bezpieczeństwem pracy jest metodą, która pozwala uporządkować i usystematyzować wszystkie działania związane z bezpieczeństwem i higieną pracy w organizacji, a jej ideą jest pełne i udokumentowane zaangażowanie zarówno kierownictwa, jak i każdego pracownika na rzecz bezpieczeństwa pracy [13]. 
Stosowanie zasad bezpieczeństwa to element sukcesu przedsiębiorstwa, który wskazuje iż przedsiębiorstwo jest odpowiedzialne społecznie w obszarze kształtowania środowiska pracy, sprawia, że pracownicy są bardziej kompetentni i zdrowi, zmniejsza koszty prowadzenia przedsiębiorstwa i zakłócenia w pracy, pomaga przedsiębiorstwom spełnić oczekiwania klientów w zakresie BHP, itp. [14].

Kształtowanie kultury bezpieczeństwa opiera się w dużej mierze na współpracy kierownictwa i pracowników. Osoby zarządzające powinny wykazywać aktywną postawę wobec problematyki BHP, ponieważ pełnią rolę kreatorów kultury bezpieczeństwa [15].

Zadowolenie $\mathrm{z}$ pracy stanowi pewien rezultat konfrontacji oczekiwań pracowników wobec wykonywanej pracy ze stosowanymi zasadami bezpieczeństwa $\mathrm{w}$ przedsiębiorstwie. Zapewnienie bezpiecznych warunków pracy jest jednym z obowiązków pracodawcy. Bezpieczne warunki pracy to również bezpieczne stanowiska pracy i środki indywidualnej ochrony pracowników. Istotne jest, aby bezpieczeństwo stanowisk zapewniało bezpieczeństwo, w zależności od rodzaju pracy na nich wykonywanej (osłony, ekrany, pomosty, zabezpieczenia przeciwpożarowe). Wprowadzenie takiego systemu zarządzania pozwala na efektywną prace całego przedsiębiorstwa.

\section{Rola menedżera w ksztaltowaniu kultury bezpieczeństwa w przedsiębiorstwie produkcyjnym}

Menedżer w procesie budowania kultury bezpieczeństwa jest kluczową postacią. Jego zakres obowiązków jest przestronny i w dużej mierze uzależniony od wielkości przedsiębiorstwa. Każdy menedżer jest odpowiedzialny za realizację celów przedsiębiorstwa, zachowanie wartości, norm i zasad kultury bezpieczeństwa pracy. Zapewnienie przez niego prawidłowych warunków pracy bhp, ich raportowanie i analiza wpływają na zdolność organizacyjna wszystkich komórek w przedsiębiorstwie.

Menedżer ds. bhp ponosi pełną odpowiedzialność za warunki pracy w przedsiębiorstwie, poprzez nieustanną kontrolę stanowisk pracy pracowników produkcyjnych, dbałość o sprawność maszyn i bezpieczeństwo dostępu do narzędzi potrzebnych do wytworzenia produktu. Jest on odpowiedzialny za błędy pracowników związanych $\mathrm{z}$ nie przestrzeganiem tych zasad, jednocześnie tym samym jest zobligowany do usunięcia powstałych nieprawidłowości związanych z nieustrzeganiem zasad bhp. 
Najważniejszym aspektem $\mathrm{w}$ pracy menedżera ds. bhp jest jego wiedza i umiejętności, a także postawy i przekonania w sferze bezpieczeństwa. Wśród warunków skutecznego kształtowania kultury bezpieczeństwa pracy można wymienić jego zaangażowanie $\mathrm{w}$ transfer wiedzy dotyczący zasad bhp, otwartą i szczerą komunikację [16].

Otwarta i szczera komunikacja opiera się na porozumiewaniu się z innymi pracownikami organizacji, przekonywaniu, uczeniu, słuchaniu, mówieniu, dochodzeniu do kompromisu czy consensusu. Komunikacja dotyczy wszystkich pracowników, na wszystkich poziomach struktury organizacyjnej. W kwestii bezpieczeństwa i higieny pracy powinna obejmować rzetelne i systematyczne informowanie o występujących zagrożeniach, środkach ochrony technicznej, a także o pożądanych zachowaniach, które umożliwią zminimalizowanie występującego ryzyka [17]. Zminimalizowanie aspektów ryzyka w przedsiębiorstwie produkcyjnym to także, nadzór nad utylizacją odpadów, współpraca z Państwową Inspekcją Pracy, Sanepidem, prowadzenie kart materiałów niebezpiecznych, odbiór linii produkcyjnych zgodnych z warunkami bezpieczeństwa.

W Polsce przedsiębiorstwa produkcyjne ze względu na prowadzony zakres działalności różnią się pod względem kultury bezpieczeństwa. Natrafiają one na podobne problemy i zagrożenia wynikające $\mathrm{z}$ zaniedbań pracowników niepostępujących zgodnie $\mathrm{z}$ zasadami bezpieczeństwa i higieny pracy, a także niewłaściwym działaniom kadry kierowniczej czy specjalistów ds. bhp, którzy działając $\mathrm{w}$ ten sposób narażają siebie i innych na niebezpieczeństwo. Wśród głównych zaniedbań zaliczyć możemy między innymi: spożywanie posiłków, picie napojów w trakcie wykonywania czynności zawodowych, palenie papierosów w miejscach do tego nieprzeznaczonych, niezakładanie ubrania ochronnego itp.

Szczególną rolę odgrywa edukowanie pracowników w zakresie bezpieczeństwa i higieny pracy. $Z$ uwagi na fakt, iż misją kierownictwa przedsiębiorstw produkcyjnych jest nadawanie istoty i uczynienia pracowników odpowiedzialnymi za własne bezpieczeństwo i zdrowie, menedżerowie ds. bhp nakreślają politykę bezpieczeństwa i higieny pracy przedsiębiorstw opartą na elementach bezpieczeństwa pracy, prawa pracy, komunikacji oraz transferu wiedzy. W tabeli 1 wyszczególniono 4 segmenty i działania własne wypracowane w przedsiębiorstwie produkcyjnym. 
Tabela 1. Segmenty polityki bezpieczeństwa i higieny pracy

\begin{tabular}{|c|c|}
\hline Obszar & Dzialania \\
\hline Bezpieczeństwo pracy & 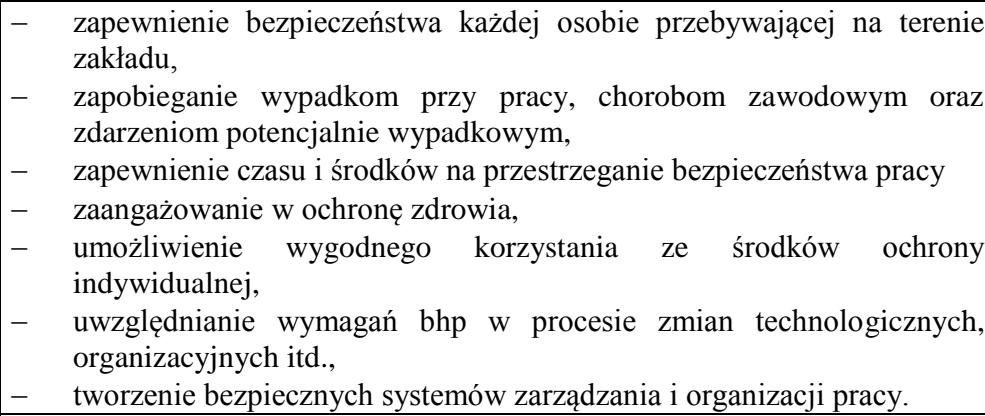 \\
\hline Przestrzeganie prawa & $\begin{array}{ll}\text { - } & \text { zobowiązanie do przestrzegania przepisów prawnych i wewnętrznych } \\
\text { regulacji, } \\
\text { - } \\
\text { - } \quad \text { biezzekące monitorowanie zmian przepisów. }\end{array}$ \\
\hline $\begin{array}{c}\text { Wzajemne } \\
\text { komunikowanie się }\end{array}$ & 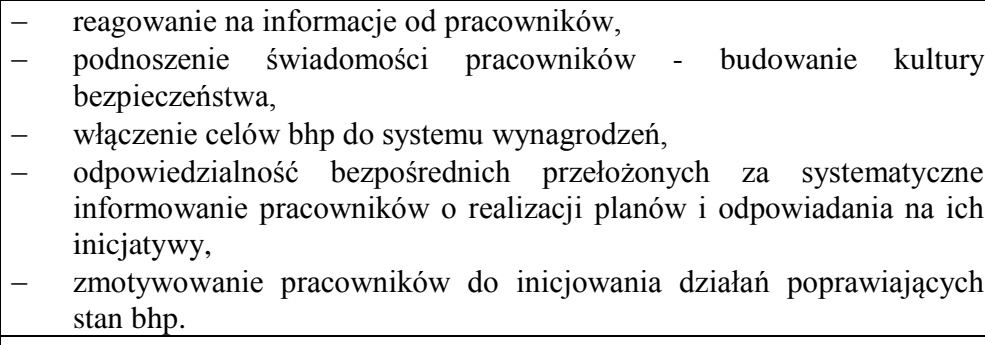 \\
\hline Ciągłe doskonalenie & $\begin{array}{ll}- & \text { stała poprawa poziomu bhp, } \\
- & \text { systematyczne sprawdzanie stanu bezpieczeństwa, } \\
- & \text { podnoszenie kwalifikacji pracowników, } \\
- & \text { promowanie kompetentnych pracowników i probezpiecznych postaw, } \\
& \text { a w szczególności odpowiedzialności za siebie i innych, } \\
\text { - } & \text { planowanie zmian odnośnie bhp. }\end{array}$ \\
\hline
\end{tabular}

Źródło: [18]

$\mathrm{Z}$ informacji przedstawionych $\mathrm{w}$ tabeli 1 wynika, iż wszystkie te działania przyczyniają się do tworzenia w przedsiębiorstwie kultury bezpieczeństwa oraz istotnej roli menedżera $\mathrm{w}$ jej kształtowaniu.

\section{Podumowanie}

Kultura bezpieczeństwa sprawia, że wartości panujące w przedsiębiorstwie są widoczne dla otoczenia przedsiębiorstwa. Kultura bezpieczeństwa to element, który ma wpływ na satysfakcję z pracy oraz wydajność organizacyjną. 
Warto jest budować kulturę bezpieczeństwa oraz umacniać pożądane postawy za pomocą spójnej komunikacji oraz wskazywanie sukcesów i zagrożeń, które są związane z codziennym działaniem pracownika w przedsiębiorstwie. Istotna jest rola menedżera ds. bezpieczeństwa i higieny pracy w przedsiębiorstwie produkcyjnym, który swoimi działaniami zapewnienia i zapobiega wypadkom, podnosi świadomość pracowników dotyczących kultury bezpieczeństwa poprzez szkolenia, a także bieżące informowanie o obowiązujących przepisach prawnych.

Zauważa, się iż w przedsiębiorstwach produkcyjnych obszar bezpieczeństwa i higieny pracy przestaje być zbiorem reguł i przepisów, a zaczyna być naturalnym nawykiem, mającym odzwierciedlenie w codziennych decyzjach i zachowaniach wszystkich pracowników.

\section{Bibliografia}

1. Szałkowski A., Bukowska U. (2005). Zarządzanie zespołami pracowniczymi. Wydawnictwo Akademii Ekonomicznej w Krakowie, Kraków.

2. Stachowicz-Stanusch A., Stanusch M. (2007). CRM przewodnik dla wdrażajacych. Placet, Warszawa.

3. Dawson C.S. (2010). Leading Culture Change. Stanford University Press, Stanford.

4. Stachowicz J., Michulik J. (2008). Dylematy procesu koniecznych zmian kultury organizacyjnej przedsiębiorstw przemystowych, Przypadek transformacji przedsiębiorstw przemystów tradycyjnych. Zarządzanie zasobami ludzkimi, 6 .

5. Szubielska J. (2013). Kultura organizacyjna i kultura bezpieczeństwa. [w:] Rakowska A. (red.) Kultura bezpieczeństwa $w$ przedsiębiorstwie, modele diagnoza i ksztattowanie. CeDeWu, Warszawa.

6. Guldenmund F.W. (2010). (Mis)understanding Safety Culture and Its Relationship to Safety Management, Risk Analysis, Caulfield East, 30, 1.

7. Amanchukwu R.N., Stanley G.J., Ololube N.P. (2015). A Review of Leadership Theories, Principles and Styles and Their Relevance to Educational Management, Management, 5, 1, 6-14.

8. Ostrom L., Wilhemsen C., Kaplan B. (1993). Assessing safety culture. Nuclear Safety, 34(2), 163-172.

9. Berends J.J. (1996). On the measurementof safety culture. Unpublished graduation, report. Eindhoven University of Technology, Eindhoven.

10. Studenski R. 2000. Kultura bezpieczeństwa pracy w przedsiębiorstwie. Bezpieczeństwo Pracy, 9.

11. Geller E.S. (1996). The psychology of safety. Chilton Book Company, Radnor, Pennsylvania.

12. Korpus J. (2006). Społeczna odpowiedzialność przedsiębiorstw w obszarze kształtowania środowiska pracy. Placet, Warszawa.

13. Pacana A. (2011). System zarządzania bezpieczeństwem i higiena pracy zgodne z PN-N18001. Wdrażanie $i$ auditowanie. Oficyna Wydawnicza Politechniki Rzeszowskiej, Rzeszów. 
14. http://osha.europa.eu/pl/publications/factsheets/77 (dostęp 04.12.2019).

15. Marcinkowski J.S., Zemfler K. (2008). Kultura bezpieczeństwa pracy $w$ firmie $w$ opinii studentów studiów niestacjonarnych. Polskie Towarzystwo Profesjologiczne, 2/2008, Uniwersytet Zielonogórski, Zielona Góra.

16. Milczarek M. (2002). Kultura bezpieczeństwa pracy. Wydawnictwo CIOP, Warszawa.

17. Ejdys J. (2010). Ksztaltowanie kultury bezpieczeństwa i higieny pracy $w$ organizacji. Oficyna Wydawnicza Politechniki Białostockiej, Białystok.

18. http://kulturabezpieczenstwa.pl/dobre-praktyki/684-bez-kompromisow-w-bhp (dostęp 07.12.2019)

\title{
THE IMPORTANCE OF A WORK SAFETY CULTURE IN A MANAGEMENT SYSTEM
}

\begin{abstract}
Shaping a culture of security in an enterprise influences the shaping of competitive advantage by the fact that managers notice the benefits of building this culture, which in turn prevents threats in the enterprise. The purpose of the article is to identify the importance of the role of managers in building a culture of security in enterprises.
\end{abstract}

Key words: organizational culture, safety culture, manager

Data przestania publikacji do Redakcji: 12.10 .2019

Data akceptacji publikacji przez Redakcję: 07.12.2019

DOI: 10.30657/qpi.2019.11.08 